\title{
Effects of Cognitive Behavioral Therapy, Existential Psychotherapy and Supportive Counselling on Facial Emotion Recognition Among Patients with Mild or Moderate Depression
}

\author{
Onur Yılmaz ${ }^{\bowtie}$, Ali Barlas Mırçık, Merve Kunduz, Müge Çombaş, \\ Ahmet Öztürk, Erdem Deveci, and İsmet Kırpınar \\ Department of Psychiatry, Bezmialem Foundation University Medical Faculty, İstanbul, Turkey
}

Objective This study compared the effects of cognitive behavioral therapy (CBT), existential psychotherapy (ExP) and supportive counseling (SUP) on facial emotion recognition among mildly and moderately depressed patients.

Methods 21 patients for CBT, and 20 each for ExP and SUP groups with 60 healthy controls were investigated. Eight consecutive weekly sessions and following two monthly boosters were performed. Prior to the sessions, all subjects received Sociodemographic Data Form, the Structured Clinical Interview for DSM-IV Axis I Disorders (SCID-1), and Facial Emotion Recognition Test (FERT). Patients received Hamilton Depression Rating Scale (HDRS) and FERT at the onset and after weekly and booster sessions.

Results Patients' ability to recognize surprised and neutral emotions were lower than controls. ExP group improved recognition of almost all emotions, CBT group improved only happy emotions and SUP group did not improve any emotions. HDRS scores declined in all patient groups, ExP and CBT groups had lower scores than SUP.

Conclusion MDD patients recognized surprised and neutral emotions lower than controls. ExP improved ability to recognize almost all emotions, CBT improved only happy emotions, SUP did not improve at all. ExP, CBT and SUP all led to a reduction in MDD. ExP and CBT had comparable effects and both were more helpful than SUP.

Psychiatry Investig 2019;16(7):491-503

Key Words Cognitive behavioral therapy, Depression, Existential psychotherapy, Facial emotion recognition, Supportive counselling.

\section{INTRODUCTION}

Nonverbal behaviors have a crucial role in expression of emotions. ${ }^{1,2}$ These behaviors include facial expressions, postures, gestures and tones of voice. ${ }^{3}$ Display of facial emotions may basically be spontaneous or controlled. Subcortical brain regions, in particular basal ganglia, and cortical regions, particularly frontal cortex are involved in both the spontaneous and controlled emotional displays. Basal ganglia and frontal cortex are reciprocally interconnected such that, damage to one of them lasts with the impairment in produc-

Received: September 3, 2018 Revised: December 19, 2018

Accepted: March 14, 2019

$\triangle$ Correspondence: Onur Yilmaz, MD

Department of Psychiatry, Bezmialem Foundation University Medical Faculty, Adnan Menderes Boulevard (Vatan Road) Fatih/İstanbul 34093 Turkey Tel: +90 533658 0934, Fax: +90 212253 1883, E-mail: ony1978@gmail.com

(c) This is an Open Access article distributed under the terms of the Creative Commons Attribution Non-Commercial License (https://creativecommons.org/licenses/bync/4.0) which permits unrestricted non-commercial use, distribution, and reproduction in any medium, provided the original work is properly cited. tion of emotional expressions. ${ }^{4}$ Frontal cortex is likely to be crucial for representing goals to either show or supress an emotional expression. The basal ganglia receive inputs from both the amygdala and other structures processing emotional information. ${ }^{4}$ Amygdala lesions reduce the display of spontaneous fearful displays to novel objects, ${ }^{5}$ however, do not affect the production of controlled fearful or other emotional displays. ${ }^{6}$

Researchers put forward that, information regarding the emotional expressions of other people is transported either by a subcortical (retinocollicular-pulvinar-amygdalar) or by a cortical pathway (retinogeniculostriate- extrastriate-fusiform) ${ }^{7.8}$ It is suggested that the subcortical pathway works fast and allows immediate automatic access of information on emotional expressions to the amygdala that can then modulate the processing of information through the cortical pathway. ${ }^{8,9}$

Recognizing facial expressions of emotions is crucial for interpersonal relationships and constitution of functional cog- 
nitions. Depression was suggested to be associated with impaired ability to recognize facial emotions. ${ }^{10}$ Inappropriate reactions to others' emotions are reported to maintain or increase depression. ${ }^{11}$ Such that, accurately identifying another person's emotional state is an ability that may be necessary not only for patients, but also for psychotherapists to empathize with patients and that may be required for obtaining valid and reliable psychotherapy process ratings in research. ${ }^{12}$ Impairments of facial emotion recognition (FER) were also shown among individuals suffering from other psychiatric disorders. A recent study reported that, adults with autism spectrum disorder uniquely misinterpreted happy faces as neutral, and were significantly more likely than typical volunteers to attribute negative valence to nonemotional faces. ${ }^{13}$ Individuals with anorexia nervosa were shown to be less accurate than healthy controls in recognizing expressions of disgust. ${ }^{14}$ Findings of another recenty study highlighted the severity and persistence of emotion recognition deficits early in the course of psychotic bipolar disorder and schizophrenia. ${ }^{15}$ To the best of our knowledge, no previous study was performed concerning the effects of psychotherapy echoles on FER.

Cognitive behavioral therapy (CBT) is widely and successfully used for major depressive disorder (MDD). CBT is developed and put into practice firstly by Beck et al. ${ }^{16}$ As time goes by, retrospective studies and reviews about CBT for depression have been added to literature. ${ }^{17,18} \mathrm{CBT}$ has enduring effects during acute phase of MDD, which is unlikely with antidepressants $(\mathrm{AD}) .{ }^{19}$ While traditional CBT was not beneficial enough in some cases, relatively new approaches on the field, called third wave CBT, have come to the scene. The terms acceptance and mindfulness, closely related to existential phylosophy, are widely used among third wave CBT literature and practice..$^{20,21}$

Existential philosopy focuses on meaning of life, freedom, authenticity and responsibility. ${ }^{22-25}$ Existential psychotherapy $(\mathrm{ExP})^{1}$ is based on existential philosophy. The interview between the therapist and the patient in an existential psychotherapy session is based on the method called phenomenology. ${ }^{26}$ Phenomenologic dialogue is a kind of invitation to the individual to let happenings and things to demonstrate themselves just like what actually they are. ${ }^{27}$

Australian psychiatrist and psychotherapist Viktor Emile Frankl is generally accepted to be the first therapist working on the basis of existential philosophy. Frankl's approach has a particular name, logotherapy (LT) ${ }^{28}$ The term "logos" is a Greek lexical item which implies 'reason' or 'plan' in English. ${ }^{29}$ LT is generally understood as 'meaning therapy'. Some other methods of existential psychotherapy are entitled as Dasein Analysis, ${ }^{30}$ Existential Group Therapy ${ }^{31}$ and Existen- tial Couple Therapy. ${ }^{32}$

A group of researchers performed unstructured forms of psychotherapy which do not help through specific psychological techniques. These therapies are commonly described in the literature as counselling or supportive therapy. Though generally accepted to be less effective than other psychotherapies, they were reported to be helpful for MDD. ${ }^{33,34}$

Since FER is reported to be poorer for MDD patients in former studies, we examined this ability throughout the study among patients, compared with healthy individuals and investigated the effects of CBT, ExP and SUP on it. We also aimed to compare the therapeutic effects of CBT, ExP and SUP for MDD. To the best of our knowledge, no studies have been performed previously concerning both these two domains.

\section{METHODS}

This study was performed at psychiatry clinics of Bezmialem Foundation University Hospital. The study protocol was approved by the local ethics committee for interventional studies (approval number: $3 / 21$ ).

\section{Subjects}

95 patients in total, diagnosed with mild or moderate MDD were included throughout the study. 61 patients $(64.2 \%)$ completed the whole protocol. The control group consisted of 60 healthy volunteers, matched with patient group for age, education, gender and marital status. All subjects were between 18 and 65 years old and reported that they were from Turkish etnics and Sunni muslims. Patients who had comorbid psychiatric disorders such as bipolar affective disorder (BPD), obsessive compulsive disorder (OCD), severe personality disorders, post traumatic stress disorder (PTSD) and substance related and addictive disorders and patients who had been on psychiatric medication from two months before the evaluation date for the study, were not included. Individuals hard to communicate, such as with blindness and deafness were not included either.

69 individuals were selected for healthy control group throughout the process. 9 out of them were excluded, due to axis-1 psychiatric disorders ( 4 individuals had depression, 2 had panic disorder, 2 had conversion disorder and 1 had somatization disorder), identified by performing SCID-1 and psychiatric examination. After making necessary explanations about the study, subjects who agreed to participate, have signed voluntary informed consent forms.

61 patients completed the whole study protocol, 21 (34.4\%) of them got CBT, 20 (32.8\%) got ExP and the rest 20 (32.8\%) got SUP for eight consecutive weekly sessions and the fol- 
lowing two monthly booster sessions. Selection of patients and therapy models were made by two separate psychiatrists who were not on the therapist list. The selection model was randomisation. Subjects were directed to groups one by one, in order of ExP, CBT and SUP.

Duration of sessions were 45 to 50 minutes. 11 patients selected for CBT (34.4\%), 13 selected for ExP (39.4\%) and 10 selected for SUP (33.3\%) did not complete the whole study.

Three patients selected for CBT, five for ExP and two for SUP did not start sessions. Two patients in CBT group, three in ExP group did not continue after their first sessions. Two patients in CBT, two in ExP and two in SUP groups were excluded from the study and directed to psychiatry clinics back, because of worsening of the symptoms to the extent that the diagnosis differed to severe MDD and they were supposed to be on psychiatric medication. One patient from ExP group had to leave the city because of a jobwechsel, after he completed four weekly sessions. Four patients in SUP, two in $\mathrm{CBT}$ and one in ExP groups left the study from second to seventh of weekly sessions. Two patients in CBT, one in ExP and two in SUP groups completed the weekly sessions, however, did not come for boosters (Table 1).

Prior to the sessions, patients received Sociodemographic Data Form prepared for the study, the Structured Clinical Interview for DSM-IV Axis 1 Disorders (SCID-1), Hamilton Depression Rating Scale (HDRS) and Facial Emotion Recognition Test (FERT). ${ }^{2}$ The control group received Sociodemographic Data Form, SCID-1 and FERT. Each patient received HDRS and FERT also after weekly and booster sessions.

\section{The Structured Clinical Interview for DSM-IV Axis 1 Disorders}

It is a form for psychiatric interview for axis-1 disorders identified in DSM-IV, structured by First et al..$^{35}$ Adaptation to Turkish and reliability analysis of Turkish form were performed by Özkürkçügil et al. ${ }^{36}$

\section{Hamilton Depression Rating Scale}

Developed originally by Hamilton for the measurement of severity of depressive symptoms, ${ }^{37}$ the structured form was developed by Williams. ${ }^{38}$ The validity and reliability study of Turkish form was made by Akdemir et al. ${ }^{39}$ The following severity ranges were recommended: no depression (0-7); mild depression (8-16); moderate depression (17-23); and severe depression $(\geq 24){ }^{40}$

\section{Facial Emotion Recognition Test}

It contains a total of 56 black and white photographs from Ekman and Friesen's catalogs, representing happy, surprised, fearful, sad, angry, disgusted and neutral facial emotions of 4 men and 4 women. ${ }^{41}$ Photo images of faces were digitized on a computer presentation via a structured query language (SQL) data application in a Visual Basic NET software program (2.4 $\mathrm{GHz}$ and $3 \mathrm{MB}$ processor, $3 \mathrm{~GB}$ main memory, 15.6-inch $\mathrm{LCD}$ screen with $1,366 \times 768$ pixel resolution). All participants seated 45 to $60 \mathrm{~cm}$ apart from the scene and performed the test in a silent, properly illuminated and ventilated room with no windows. There was an array of colours under each facial expression scene (Figure 1). Each expression matched with a

Table 1. Flowchart for numbers of patients detached from study, reasons of detachment and numbers of patients left

\begin{tabular}{clll}
\hline Time & ExP $(\mathrm{N})$ & CBT $(\mathrm{N})$ & SUP $(\mathrm{N})$ \\
\hline St & 33 & 32 & 30 \\
W1 & $28(5 \mathrm{dns})$ & $29(3 \mathrm{dns})$ & $28(2 \mathrm{dns})$ \\
W2 & $25(3 \mathrm{dnc})$ & $27(2 \mathrm{dnc})$ & 28 \\
W3 & $23(2 \mathrm{sbm})$ & $25(2 \mathrm{sbm})$ & $26(2 \mathrm{sbm})$ \\
W4 & 23 & 25 & 26 \\
W5 & $22(1 \mathrm{lc})$ & $24(1 \mathrm{dnc})$ & $24(2 \mathrm{dnc})$ \\
W6 & 22 & 24 & 24 \\
W7 & $21(1 \mathrm{dnc})$ & $23(1 \mathrm{dnc})$ & $22(2 \mathrm{dnc})$ \\
W8 & 21 & 23 & 22 \\
B1 & $20(1 \mathrm{dncb})$ & $21(2 \mathrm{dncb})$ & $20(2 \mathrm{dncb})$ \\
B2 & 20 & 21 & 20 \\
\hline
\end{tabular}

Number of patients who left the study are presented alongside the reasons in parantheses. ExP: existential psychotherapy, CBT: cognitive behavioral therapy, SUP: supportive counselling, N: number of patients, St: number before sessions started, W: weekly sessions, B: booster sessions, dns: did not start, dnc: did not continue, sbm: sent back to clinics for possible medication, lc: left the city because of a jobwechsel, dncb: did not continue for boosters

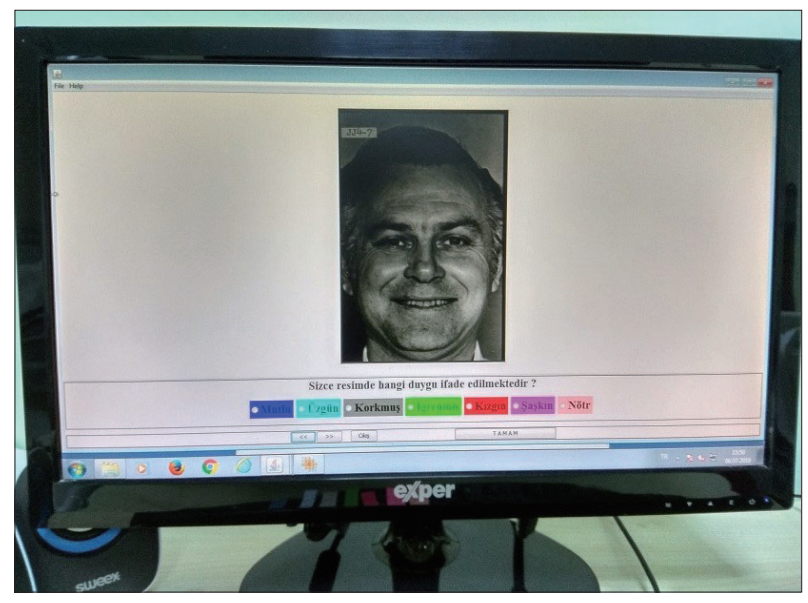

Figure 1. The question in Turkish below the photograph on the scene can be translated to English as follows: "Which emotion do you think is expressed on the current scene?." Below the question, there are coloured boxes including the names of the emotions written in Turkish. Colours of boxes and the names of the relevant emotions in English from left to right are as follows. Blue: Happy, Light Blue: Sad, Grey: Fearful, Green: Disgusted, Red: Angry, Pink: Surprised, Light Pink: Neutral. 


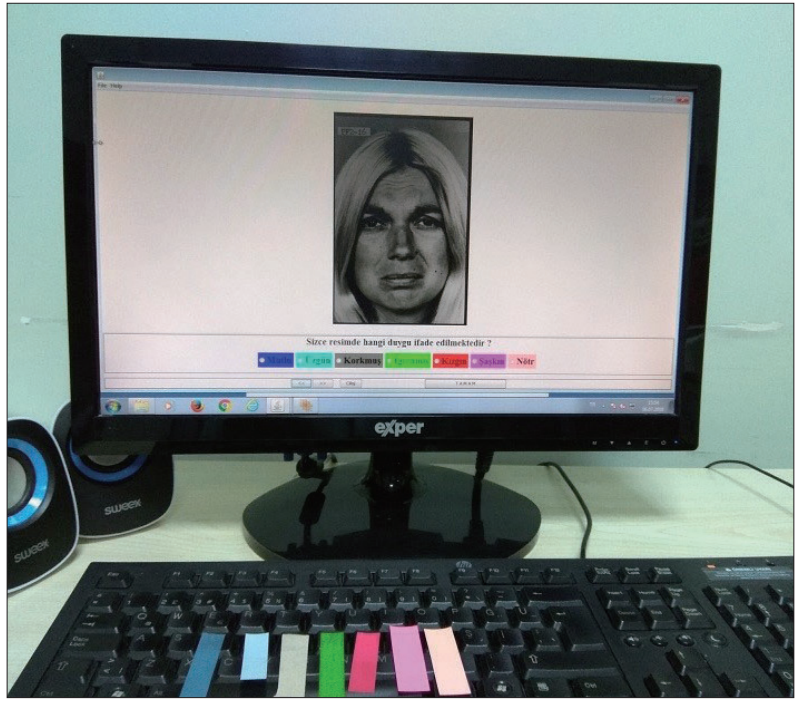

Figure 2. The computer screen (demonstrating the photograph, question in Turkish asking the relevant emotion and coloured boxes below the question) and the keyboard with sticked adhesive notepapers (coloured identical with their counterparts on the scene) are seen in the figure. The sequential letters on which the notepapers have been sticked are; D, F, G, H, J, K, and L. separate certain colour on the array and a certain button on the keyboard. We sticked self adhesive notepapers on each of these buttons, coloured identical with their counterparts on the computer scene (Figure 2). Facial expressions on the first seven certain photographs were told to the participants in order to accommodate them to the test. For the resting 49 photographs, the participant chose one emotion and pressed the related key, then, the subsequent photograph automatically displayed on the scene. Participants were not told about the correct total number of any emotions. Thus, the possible tendency for a certain expression was inhibited. Likewise, participants received no feedback during their turn. Immediately after the test finished, the programme produced an excel file with records of all answers.

\section{Therapists and sessions}

Before study beginned, flowcharts for ExP and CBT were prepared by participation of all therapists (Table 2 and 3 ). There was no flowchart for SUP. There were two therapists each for CBT and ExP an one for SUP. The durations of ex-

Table 2. Flowchart for CBT sessions

\begin{tabular}{|c|c|}
\hline Session number & Content of session in brief \\
\hline W1 & $\begin{array}{l}\text { Noting current complaints, getting brief knowledge about patient's history of disorder, pharmacotherapy and } \\
\text { psychotherapy (if any), showing some cognitive contradictions, setting appropriate and available targets, proposing } \\
\text { treatment rationale for the agenda. }\end{array}$ \\
\hline W2 & $\begin{array}{l}\text { Discussing available cognitive contradictions and showing some more, mentioning the term "automatic thoughts" and } \\
\text { deriving them from existing contradictions, demonstrating possible initiating, triggering and maintaininig factors, } \\
\text { setting homework(s). }\end{array}$ \\
\hline W3 & $\begin{array}{l}\text { Evaluation of homework(s) exploring more automatic thoughts and evaluating alternative thoughts against them, } \\
\text { elaborating triggering and maintaining factors setting new homework(s). }\end{array}$ \\
\hline W4 & $\begin{array}{l}\text { Evaluation of homework(s) testing certain automatic thoughts and elaborating more, evaluating alternative thoughts, } \\
\text { retracing triggering and maintaining factors setting new homework(s). }\end{array}$ \\
\hline W5 & $\begin{array}{l}\text { Evaluation of homework(s), testing and evaluating more (new, if explored any) automatic thoughts, elaborating and } \\
\text { retracing initiating factors, mentioning the term "intermediary beliefs" and deriving some of them from outcomes until } \\
\text { then, setting new homework(s). }\end{array}$ \\
\hline W6 & $\begin{array}{l}\text { Evaluation of homework(s), elaborating and testing intermediary beliefs evaluating original and current targets setting } \\
\text { new homework(s). }\end{array}$ \\
\hline W7 & $\begin{array}{l}\text { Evaluation of homework(s), testing more (new, if explored any) intermediary beliefs retracing initiating factors, setting } \\
\text { new homework(s). }\end{array}$ \\
\hline W8 & $\begin{array}{l}\text { Evaluation of homework(s), overall assessment of alternative automatic thoughts and intermediary beliefs, overall } \\
\text { assessment of original and current targets, setting new (monthly) homework(s). }\end{array}$ \\
\hline B1 & $\begin{array}{l}\text { Evaluation of homework(s), overall assessment of alternative automatic thoughts and intermediary beliefs *mentioning } \\
\text { the term "core beliefs" and deriving some from intermediary beliefs (if needed), overall assessment of original and } \\
\text { current targets, setting new (monthly) homework(s). }\end{array}$ \\
\hline B2 & $\begin{array}{l}\text { Overall assessment of alternative automatic thoughts and intermediary beliefs (and core beliefs if needed), overall } \\
\text { assessment of original and current targets, evaluating how to use new skills in case of relapse and recurrence. }\end{array}$ \\
\hline
\end{tabular}

Despite following this flowchart, sessions were flexible to some extent, according to patients' needs and circumstances. Hamilton Depression Rating Scale and Facial Emotion Recognition Test were repeated after W8 and B2. *core beliefs are not usually needed to be explored for mild and moderate depression. CBT: cognitive behavioral therapy, W: weekly session, B: booster session 
Table 3. Flowchart for ExP sessions

\begin{tabular}{|c|c|}
\hline Session number & Content of session in brief \\
\hline W1 & $\begin{array}{l}\text { Noting current complaints, getting brief knowledge about patient's history of disorder, pharmacotherapy and } \\
\text { psychotherapy (if any), introducing basic route for ExP and assessing suitability of patient. }\end{array}$ \\
\hline W2 & $\begin{array}{l}\text { Letting the patient give more details of complaints, trying to cover how authentic is patient's life and which obstacles are } \\
\text { working against authenticity, trying to cover which aspects of patient's life are already close to authenticity. }\end{array}$ \\
\hline W3 & $\begin{array}{l}\text { Structuring the therapeutic dialogue on phenomenologic basis, exploring intangible statements and directing the patient } \\
\text { to embody his/her speech, demonstrating how apart the patient is from or how close to authenticity in certain fields. }\end{array}$ \\
\hline W4 & $\begin{array}{l}\text { Improving the phenomenologic dialogue, improving embodiment of patient's statements, assessment for patient's stance } \\
\text { toward self-relatedness, directing the patient to express him/herself including physical, relational and spiritual fields of } \\
\text { living. }\end{array}$ \\
\hline W5 & $\begin{array}{l}\text { Improving the phenomenologic dialogue, exploring curbs resulting from avoiding embodiment, exploring the patient's } \\
\text { stance toward responsibility and choices of life. }\end{array}$ \\
\hline W6 & $\begin{array}{l}\text { Improving the phenomenologic dialogue trying to receive feedbacks concerning patient's certain patterns interfering with } \\
\text { functionality, exploring curbs resulting from avoiding responsibility, directing the patient to negotiate about taking the } \\
\text { responsibility of his/her choices. }\end{array}$ \\
\hline W7 & $\begin{array}{l}\text { Improving the phenomenologic dialogue inviting the patient to give feedbacks about his/her patterns interfering with } \\
\text { functionality, exploring curbs resulting from avoiding responsibility and freedom, directing the patient to negotiate about } \\
\text { taking the responsibility of predictible and unpredictible outcomes of his/her choices. }\end{array}$ \\
\hline W8 & $\begin{array}{l}\text { Improving the phenomenologic dialogue inviting the patient to give feedbacks about his/her feelings about the sessions } \\
\text { and the therapist, exploring strengths of the patients that might have been gained through enhanced sense of } \\
\text { responsibility, inviting the patient to negotiate about his/her fears concerning freedom. }\end{array}$ \\
\hline B1 & $\begin{array}{l}\text { Evaluation of experiences until session date, overall assessment of the patient's stance toward responsibility, authenticity } \\
\text { and freedom, overall assessment of patient's stance toward desirable and undesirable experiences, directing the patient to } \\
\text { talk about his/her experiences with minimized labels and habitual attitudes. }\end{array}$ \\
\hline B2 & $\begin{array}{l}\text { Evaluation of experiences until session date, overall assessment of the patient's stance toward responsibility, authenticity } \\
\text { and freedom, overall assessment of patient's stance toward his/her will to look for living a meaningful life, assessment of } \\
\text { patient's approach about habitual reactions and labeling his/her experiences, evaluating how to use new skills in case of } \\
\text { relapse and recurrence. }\end{array}$ \\
\hline
\end{tabular}

Despite following this flowchart, sessions were flexible to some extent, according to patients' needs and circumstances. Hamilton Depression Rating Scale and Facial Emotion Recognition Test were repeated after W8 and B2. ExP: existential psychotherapy, W: weekly session, B: booster session

perience as psychotherapists and the number of patients with whom they performed and completed sessions were as follows: 2 years (10 patients) and 6 years (11 patients) for CBT therapists, 2 years (9 patients) and 5 years (11 patients) for ExP therapists and 4 years (20 patients all) for SUP therapist. Thus, we tried to reduce the possible unevenness regarding the therapy offered to patients.

\section{Statistics}

While response to the therapy was measured via changes in HDRS and FERT scores, when power analysis was assessed with power value of 0.80 and significance level of 0.05 , a minimum of 16 patients were required for each of three groups. We eventually decided for 20 subjects in each group, as the optimal value. One additional patient completed CBT.

Statistical evaluation was done with IBM SPSS Statistics 24 package program. All numerical variables were expressed as either mean ranks or means \pm standard deviations, while cat- egorical variables were expressed with frequency and possibility tables.

Given more than two independent groups and relatively limited number of subjects in each patient group, KruskalWallis was used for comparison of numerical and chi-square was used for categorical variables. When significant differences between groups were detected with Kruskal-Wallis, each group were paired with another and compared with MannWhitney $\mathrm{U}$ test. Comparisons of groups in themselves were made by Wilcoxon Signed Rank Test. Probability value (p) was taken as $<0.05$ for statistical significance in all analyses.

\section{RESULTS}

All three patient groups and control group were matched in terms of age, gender, marital status and education (Table 4). SCID results and psychiatric examination revealed that, among patients who completed the whole study programme, 
Table 4. Comparison of sociodemographic data of patient and control groups

\begin{tabular}{|c|c|c|c|c|c|}
\hline Demographical data & $\operatorname{ExP}(\mathrm{N}=20)$ & $\mathrm{CBT}(\mathrm{N}=21)$ & $\operatorname{SUP}(\mathrm{N}=20)$ & Controls $(\mathrm{N}=60)$ & $\mathrm{p}$ \\
\hline Age & $32.4 \pm 13.1$ & $30.9 \pm 10.2$ & $33.0 \pm 11.8$ & $37.3 \pm 10.7$ & 0.326 \\
\hline \multicolumn{6}{|l|}{ Gender (\%) } \\
\hline Female & $18(90.0)$ & $18(85.7)$ & $17(85.0)$ & $49(81.7)$ & 0.839 \\
\hline \multicolumn{6}{|l|}{ Marital status (\%) } \\
\hline Married & $7(35.0)$ & $5(23.8)$ & $9(45.0)$ & $15(25.0)$ & \\
\hline Single & $11(55.0)$ & $14(66.7)$ & $10(50.0)$ & $38(63.3)$ & 0.703 \\
\hline Divorced, widow, seperated & $2(10.0)$ & $2(9.5)$ & $1(5.0)$ & $7(11.7)$ & \\
\hline \multicolumn{6}{|l|}{ Education (\%) } \\
\hline Literate & $1(5.0)$ & $1(4.8)$ & $0(0.0)$ & $2(3.3)$ & \\
\hline Elementary & $3(15.0)$ & $3(14.3)$ & $3(15.0)$ & $16(26.7)$ & \\
\hline High school & $5(25.0)$ & $4(19.0)$ & $7(35.0)$ & $14(23.3)$ & 0.697 \\
\hline Associate licence, licence & $10(50.0)$ & $11(52.4)$ & $8(40.0)$ & $18(30.0)$ & \\
\hline Post-graduate, doctorate & $1(5.0)$ & $2(9.5)$ & $2(10.0)$ & $10(16.7)$ & \\
\hline
\end{tabular}

Kruskal-Wallis was used for comparison of numerical data and chi-square test was used for comparison of categorical variables. Ages of groups are expressed as mean \pm standard deviation. Other values are expressed as percentiles. N: number of subjects, p: probability value, ExP: existential psychotherapy group, CBT: cognitive behavioral therapy group, SUP: supportive counselling group

Table 5. Comparison of mean ranks of HDRS scores between patient groups

\begin{tabular}{ccccc}
\hline Time of measurement & ExP $(\mathrm{N}=20)$ & CBT $(\mathrm{N}=21)$ & SUP $(\mathrm{N}=20)$ & $\mathrm{p}$ \\
\hline Bgn & 30.98 & 29.12 & 33.00 & 0.781 \\
Awk & 20.90 & 27.62 & 44.65 & $<0.01$ \\
ABst & 23.30 & 24.52 & 45.50 & 0.021 \\
\hline
\end{tabular}

Kruskal-Wallis was used for comparison of numerical data. Significant differences are demonstrated with bold characters. HDRS: Hamilton Depression Rating Scale, N: number of subjects, p: probability value, ExP: existential psychotherapy group, CBT: cognitive behavioral therapy group, SUP: supportive counselling group, Bgn: mean rank for HDRS scores before the start of sessions, Awk: mean rank for HDRS scores after weekly sessions, Abst: mean rank for HDRS scores after booster sessions

Table 6. Paired comparisons of mean HDRS ranks of each patient groups

\begin{tabular}{|c|c|c|c|c|c|c|}
\hline \multirow{2}{*}{ Time of measurement } & \multicolumn{2}{|c|}{ ExP vs. SUP } & \multicolumn{2}{|c|}{ CBT vs. SUP } & \multicolumn{2}{|c|}{ ExP vs. CBT } \\
\hline & $\mathrm{m}$ & $\mathrm{p}$ & $\mathrm{m}$ & $\mathrm{p}$ & $\mathrm{m}$ & $\mathrm{p}$ \\
\hline Bgn & 19.88 vs. 21.13 & 0.738 & 19.69 vs. 22.38 & 0.472 & 21.60 vs. 20.43 & 0.753 \\
\hline Awk & 13.15 vs. 27.85 & $<0.01$ & 15.00 vs. 27.30 & $<0.01$ & 18.25 vs. 23.62 & 0.146 \\
\hline ABst & 13.45 vs. 27.55 & $<0.01$ & 13.90 vs. 28.45 & $<0.01$ & 20.35 vs. 21.62 & 0.733 \\
\hline
\end{tabular}

Mann-Whitney U was used for comparison of numerical data. Significant differences are demonstrated with bold characters. HDRS: Hamilton Depression Rating Scale, P: probability value, ExP: existential psychotherapy group, CBT: cognitive behavioral therapy group, SUP: supportive counselling group, vs: versus, Bgn: mean values before the start of sessions, Awk: mean values after weekly sessions, Abst: mean values after booster sessions, m: mean rank

7 from ExP, 7 from CBT and 10 from SUP were diagnosed with mild depression while 13 from ExP, 14 from CBT and 10 from SUP group had moderate depression. Some patients who had prediagnoses of depression in psychiatry clinics and directed to evaluation for the study were not included due to the results obtained from psychiatric examination and SCID1. 2 of them had OCD, 1 had PTSD, 1 had generalized anxiety disorder and 1 had alcohol use disorder as comorbid diseases to depression. Besides, after performing SCID-1 and detailed psychiatric examination and taking information of psychiatric history, 3 patients were found to have BPD and 1 was found to have severe major depression with psychotic signs. So, they were not included either.

At the end of the study, mean rank of HDRS scores demonstrated significant differences between patient groups $(\mathrm{p}<0.05)$ (Table 5). When the groups were compared in pairs, significant differences were found between ExP-SUP and CBT-SUP, however, the difference between ExP and CBT groups was not significant (Table 6). All patient groups were compared in themselves and were found to have lower mean scores of HDRS at the end of booster sessions than the beginning. Mean HDRS scores did not change significantly between the end of weekly and booster sessions in ExP and SUP, while CBT group demonstrated a significant decrease 
in this period (Table 7).

There were significant differences of the ability of individuals to recognize surprised and neutral facial emotions before the sessions start, between patient and control groups (Table
7). When patient groups were compared after weekly and booster sessions, significant differences were found in sad, disgusted, angry, surprised and neutral emotions (Table 8). Subsequently, all patient groups were compared in pairs. ExP

Table 7. Comparisons of mean HDRS scores for all treatment groups in themselves

\begin{tabular}{|c|c|c|c|c|c|c|}
\hline \multirow{2}{*}{ Comparison } & \multicolumn{2}{|l|}{$\operatorname{ExP}(\mathrm{N}=20)$} & \multicolumn{2}{|l|}{ CBT $(\mathrm{N}=21)$} & \multicolumn{2}{|l|}{ SUP $(N=20)$} \\
\hline & Mean & $\mathrm{p}$ & Mean & $\mathrm{p}$ & Mean & $\mathrm{p}$ \\
\hline Bgn vs. ABst & $(13.1 \pm 4.0)$ vs. $(7.3 \pm 4.0)$ & $<0.01$ & $(12.6 \pm 3.6)$ vs. $(7.3 \pm 3.2)$ & $<0.01$ & $(13.4 \pm 3.8)$ vs. $(10.0 \pm 3.3)$ & 0.025 \\
\hline Bgn vs. Awk & $(13.1 \pm 4.0)$ vs. $(7.9 \pm 2.7)$ & $<0.01$ & $(12.6 \pm 3.6)$ vs. $(8.7 \pm 3.1)$ & $<0.01$ & (13.4 \pm 3.7$)$ vs. $(11.5 \pm 3.5)$ & 0.189 \\
\hline Awk vs. ABst & $(7.9 \pm 2.7)$ vs. $(7.3 \pm 4.0)$ & 0.322 & $(8.7 \pm 3.1)$ vs. $(7.3 \pm 3.2)$ & $<0.01$ & $(11.5 \pm 3.5)$ vs. $(10.0 \pm 3.3)$ & 0.052 \\
\hline
\end{tabular}

Wilcoxon Signed Rank Test was used for comparison of numerical data. HDRS scores are expressed as mean \pm standard deviation. Significant differences are demonstrated with bold characters. HDRS: Hamilton Depression Rating Scale, N: number of subjects, p: probability value, ExP: existential psychotherapy group, CBT: cognitive behavioral therapy group, SUP: supportive counselling group, vs: versus, Bgn: mean values before the start of sessions, Awk: mean values after weekly sessions, Abst: mean values after booster sessions

Table 8. Comparison of mean ranks of facial emotion recognitions between all groups

\begin{tabular}{|c|c|c|c|c|c|}
\hline Emotion & $\operatorname{ExP}(\mathrm{N}=20)$ & CBT (N=21) & $\operatorname{SUP}(\mathrm{N}=20)$ & Control & $\mathrm{p}$ \\
\hline \multicolumn{6}{|l|}{ Happy } \\
\hline Bgn & 54.88 & 52.81 & 58.60 & 66.71 & 0.268 \\
\hline Awk & 32.13 & 30.05 & 30.88 & & 0.899 \\
\hline ABst & 32.98 & 29.64 & 30.45 & & 0.739 \\
\hline \multicolumn{6}{|l|}{ Sad } \\
\hline Bgn & 61.80 & 67.98 & 53.45 & 60.81 & 0.577 \\
\hline Awk & 38.98 & 37.29 & 16.48 & & $<0.01$ \\
\hline ABst & 37.70 & 35.81 & 19.25 & & $<0.01$ \\
\hline \multicolumn{6}{|l|}{ Fearful } \\
\hline Bgn & 57.48 & 68.19 & 48.35 & 63.88 & 0.230 \\
\hline Awk & 34.65 & 31.19 & 27.15 & & 0.383 \\
\hline ABst & 33.38 & 31.50 & 28.10 & & 0.617 \\
\hline \multicolumn{6}{|l|}{ Disgusted } \\
\hline Bgn & 58.93 & 56.71 & 53.88 & 65.57 & 0.505 \\
\hline Awk & 38.60 & 27.62 & 26.95 & & 0.057 \\
\hline ABst & 40.00 & 25.71 & 27.55 & & 0.017 \\
\hline \multicolumn{6}{|l|}{ Angry } \\
\hline Bgn & 69.23 & 54.81 & 52.80 & 63.16 & 0.318 \\
\hline Awk & 41.50 & 29.67 & 21.90 & & $<0.01$ \\
\hline ABst & 39.30 & 31.62 & 22.05 & & $<0.01$ \\
\hline \multicolumn{6}{|l|}{ Surprised } \\
\hline Bgn & 45.43 & 50.74 & 46.65 & 74.57 & $<0.01$ \\
\hline Awk & 40.60 & 27.79 & 24.78 & & $<0.01$ \\
\hline ABst & 39.18 & 28.98 & 24.95 & & 0.027 \\
\hline \multicolumn{6}{|l|}{ Neutral } \\
\hline Bgn & 40.45 & 49.43 & 42.43 & 78.09 & $<0.01$ \\
\hline Awk & 42.75 & 28.60 & 21.78 & & $<0.01$ \\
\hline ABst & 42.68 & 28.45 & 22.00 & & $<0.01$ \\
\hline
\end{tabular}

Kruskal-Wallis was used for comparison of numerical data. Significant differences are demonstrated with bold characters. N: number of subjects, p: probability value, ExP: existential psychotherapy group, CBT: cognitive behavioral therapy group, SUP: supportive counselling group, Bgn: mean ranks before sessions start, Awk: mean ranks after weekly sessions, Abst: mean ranks after booster sessions 
Table 9. Paired comparisons of mean ranks of facial emotion recognitions after weekly and booster sessions between patient groups

\begin{tabular}{|c|c|c|c|c|c|c|}
\hline \multirow{2}{*}{ Emotion } & \multicolumn{2}{|c|}{ ExP vs. SUP } & \multicolumn{2}{|c|}{ CBT vs. SUP } & \multicolumn{2}{|c|}{ ExP vs. CBT } \\
\hline & $\mathrm{m}$ & $\mathrm{p}$ & $\mathrm{m}$ & $\mathrm{p}$ & $\mathrm{m}$ & $\mathrm{p}$ \\
\hline \multicolumn{7}{|l|}{ Happy } \\
\hline Awk & 20.85 vs. 20.15 & 0.814 & 20.79 vs. 21.23 & 0.887 & 21.78 vs. 20.26 & 0.622 \\
\hline ABst & 21.28 vs. 19.73 & 0.593 & 20.79 vs. 21.23 & 0.887 & 22.20 vs. 19.86 & 0.434 \\
\hline \multicolumn{7}{|l|}{ Sad } \\
\hline Awk & 28.15 vs. 12.85 & $<0.01$ & 27.55 vs. 14.13 & $<0.01$ & 21.28 vs. 20.74 & 0.873 \\
\hline ABst & 26.90 vs. 14.10 & $<0.01$ & 26.10 vs. 15.65 & $<0.01$ & 21.30 vs. 20.71 & 0.862 \\
\hline \multicolumn{7}{|l|}{ Fearful } \\
\hline Awk & 23.00 vs. 18.00 & 0.161 & 22.29 vs. 19.65 & 0.466 & 22.15 vs. 19.90 & 0.533 \\
\hline ABst & 22.78 vs. 18.73 & 0.321 & 22.07 vs. 19.88 & 0.546 & 21.60 vs. 20.43 & 0.746 \\
\hline \multicolumn{7}{|l|}{ Disgusted } \\
\hline Awk & 24.18 vs. 16.83 & 0.041 & 21.36 vs. 20.63 & 0.840 & 24.93 vs. 17.26 & 0.035 \\
\hline Abst & 24.83 vs. 16.48 & 0.026 & 20.45 vs. 21.58 & 0.756 & 25.98 vs. 16.26 & $<0.01$ \\
\hline \multicolumn{7}{|l|}{ Angry } \\
\hline Awk & 26.40 vs. 14.60 & $<0.01$ & 24.05 vs. 17.80 & 0.082 & 25.60 vs. 16.62 & 0.01 \\
\hline ABst & 25.95 vs. 15.05 & $<0.01$ & 24.33 vs. 17.50 & 0.057 & 23.85 vs. 18.29 & 0.106 \\
\hline \multicolumn{7}{|l|}{ Surprised } \\
\hline Awk & 25.85 vs. 15.15 & $<0.01$ & 21.83 vs. 20.13 & 0.637 & 25.25 vs. 16.95 & 0.021 \\
\hline ABst & 25.33 vs. 15.68 & $<0.01$ & 22.17 vs. 19.78 & 0.513 & 24.35 vs. 17.81 & 0.070 \\
\hline \multicolumn{7}{|l|}{ Neutral } \\
\hline Awk & 27.03 vs. 13.98 & $<0.01$ & 23.57 vs. 18.30 & 0.143 & 26.23 vs. 16.02 & $<0.01$ \\
\hline ABst & 27.00 vs. 14.00 & $<0.01$ & 23.38 vs. 18.50 & 0.179 & 26.18 vs. 16.07 & $<0.01$ \\
\hline
\end{tabular}

Mann-Whitney U was used for comparison of numerical data. Significant differences are demonstrated with bold characters. P: probability value, m: mean rank, ExP: existential psychotherapy group, CBT: cognitive behavioral therapy group, SUP: supportive counselling group, vs: versus, Awk: mean values after weekly sessions, Abst: mean values after booster sessions

was superior to SUP in all emotions except happy and fearful, both after weekly and booster sessions. CBT was superior to SUP only for sad emotions. Crucially, ExP provided significantly more improvement than CBT, in recognition of disgusted and neutral emotions both after weekly and booster and in angry and surprised emotions after weekly sessions (Table 9). Moreover, each group has been compared in themselves. After booster sessions, ExP group enhanced their ability in recognizing all the emotions except anger, CBT group enhanced recognition of happy emotions only, however, SUP group did not demonstrate any enhancement (Table 10).

\section{DISCUSSION}

Depressive disorders relapse frequently, besides, their recurrence rate is remarkable. ${ }^{42}$ As time progresses, the tendency to accept depression as a lifelong course is growing. Further, there are editorials supporting this approach. ${ }^{43}$ The recurrence rate in first episode depression is reported to be $40 \%$ to $60 \%$ and after the third episode, the rate reaches up to
90\% ${ }^{44}$ Considering the increasing morbidity and mortality by each relapse and recurrence of $\mathrm{MDD},{ }^{45}$ it is of critical importance to choose treatments which seem to be helpful to prevent from relapses and recurrences.

Various practices were reported about the average treatment duration in CBT. Shapiro et al. ${ }^{46}$ conducted a major study comparing the efficacy of CBT and psychodynamic interpersonal therapy (PIT) for depression. In this study, duration of treatment was experimentally manipulated (8 sessions versus 16 sessions). At the end of treatment, CBT and PIT were equally effective. However, one year after treatment completed, patients who received 8 sessions of PIT did worse on almost all treatment measures compared with 8 session CBT, 16 session CBT and 16 session PIT. That is, no significant difference was found between 8 and 16 sessions of CBT. Ilardi and Creighead ${ }^{47}$ reported that, symptom improvement in CBT predominantly occurs in first 4 weeks. DeRubeis and Feeley ${ }^{48}$ measured how much time and effort CBT therapists spent on cognitive modification in different therapy sessions. They found that, therapists spent essentially the same amount 
Table 10. Comparisons of mean values of recognized facial emotions for each group in themselves

\begin{tabular}{|c|c|c|c|c|c|c|}
\hline \multirow{2}{*}{ Comparison } & \multicolumn{2}{|l|}{ ExP } & \multicolumn{2}{|l|}{ CBT } & \multicolumn{2}{|l|}{ SUP } \\
\hline & Mean & $\mathrm{p}$ & Mean & $\mathrm{P}$ & Mean & $\mathrm{p}$ \\
\hline \multicolumn{7}{|l|}{ Bgn vs. ABst } \\
\hline Happy & $(6.0 \pm 0.9)$ vs. $(6.7 \pm 0.6)$ & $<0.01$ & $(5.8 \pm 1.2)$ vs. $(6.5 \pm 0.8)$ & 0.020 & $(6.2 \pm 0.8)$ vs. $(6.4 \pm 1.0)$ & 0.166 \\
\hline Sad & $(6.0 \pm 1.0)$ vs. $(6.4 \pm 0.6)$ & 0.046 & $(6.2 \pm 1.0)$ vs. $(6.3 \pm 1.0)$ & 0.605 & $(5.8 \pm 1.2)$ vs. $(5.3 \pm 1.6)$ & 0.216 \\
\hline Fearful & $(5.1 \pm 1.5)$ vs. $(5.7 \pm 1.1)$ & 0.025 & $(5.5 \pm 1.4)$ vs. $(5.6 \pm 1.3)$ & 0.773 & $(5.0 \pm 1.3)$ vs. $(5.3 \pm 1.4)$ & 0.245 \\
\hline Disgusted & $(4.7 \pm 1.5)$ vs. $(5.5 \pm 1.2)$ & $<0.01$ & $(4.6 \pm 1.7)$ vs. $(4.4 \pm 1.5)$ & 0.406 & $(4.5 \pm 1.5)$ vs. $(4.6 \pm 1.4)$ & 0.954 \\
\hline Angry & $(6.3 \pm 1.1)$ vs. $(6.5 \pm 0.7)$ & 0.463 & $(5.9 \pm 1.1)$ vs. $(6.1 \pm 0.9)$ & 0.392 & $(5.9 \pm 1.1)$ vs. $(5.5 \pm 1.1)$ & 0.179 \\
\hline Surprised & $(4.0 \pm 1.5)$ vs. $(5.6 \pm 0.9)$ & $<0.01$ & $(4.2 \pm 1.4)$ vs. $(4.8 \pm 1.5)$ & 0.124 & $(4.1 \pm 1.7)$ vs. $(4.5 \pm 1.3)$ & 0.237 \\
\hline Neutral & $(3.8 \pm 1.5)$ vs. $(5.6 \pm 0.9)$ & $<0.01$ & $(4.2 \pm 1.6)$ vs. $(4.7 \pm 1.2)$ & 0.222 & $(4.1 \pm 1.4)$ vs. $(4.0 \pm 1.4)$ & 0.660 \\
\hline \multicolumn{7}{|l|}{ Bgn vs. Awk } \\
\hline Happy & $(6.0 \pm 0.9)$ vs. $(6.6 \pm 0.6)$ & $<0.01$ & $(5.8 \pm 1.2)$ vs. $(6.4 \pm 0.8)$ & 0.031 & $(6.2 \pm 0.8)$ vs. $(6.3 \pm 1.0)$ & 0.564 \\
\hline Sad & $(6.0 \pm 1.0)$ vs. $(6.3 \pm 0.7)$ & 0.218 & $(6.2 \pm 1.0)$ vs. $(6.3 \pm 0.8)$ & 0.485 & $(5.8 \pm 1.2)$ vs. $(4.9 \pm 1.2)$ & $0.022 *$ \\
\hline Fearful & $(5.1 \pm 1.5)$ vs. $(5.7 \pm 1.2)$ & 0.032 & $(5.5 \pm 1.4)$ vs. $(5.4 \pm 1.2)$ & 0.724 & $(5.0 \pm 1.3)$ vs. $(5.1 \pm 1.3)$ & 0.600 \\
\hline Disgusted & $(4.7 \pm 1.5)$ vs. $(5.2 \pm 1.2)$ & 0.88 & $(4.6 \pm 1.7)$ vs. $(4.2 \pm 1.4)$ & 0.221 & $(4.5 \pm 1.5)$ vs. $(4.4 \pm 1.5)$ & 0.623 \\
\hline Angry & $(6.3 \pm 1.1)$ vs. $(6.4 \pm 0.7)$ & 0.744 & (5.9 \pm 1.1$)$ vs. $(5.9 \pm 0.8)$ & 0.971 & $(5.9 \pm 1.1)$ vs. $(5.1 \pm 1.2)$ & $0.038^{*}$ \\
\hline Surprised & $(4.0 \pm 1.5)$ vs. $(6.4 \pm 0.6)$ & $<0.01$ & $(4.2 \pm 1.4)$ vs. $(4.6 \pm 1.5)$ & 0.308 & $(4.1 \pm 1.7)$ vs. $(4.3 \pm 1.3)$ & 0.440 \\
\hline Neutral & $(3.8 \pm 1.5)$ vs. $(5.3 \pm 1.0)$ & $<0.01$ & $(4.2 \pm 1.6)$ vs. $(4.8 \pm 1.3)$ & 0.155 & $(4.1 \pm 1.4)$ vs. $(3.9 \pm 1.4)$ & 0.383 \\
\hline \multicolumn{7}{|l|}{ Awk vs. ABst } \\
\hline Happy & $(6.6 \pm 0.6)$ vs. $(6.7 \pm 0.6)$ & 0.317 & $(6.4 \pm 0.8)$ vs. $(6.5 \pm 0.8)$ & 0.564 & $(6.3 \pm 1.0)$ vs. $(6.4 \pm 1.0)$ & 0.083 \\
\hline Sad & $(6.3 \pm 0.7)$ vs. $(6.4 \pm 0.6)$ & 0.083 & $(6.3 \pm 0.8)$ vs. $(6.3 \pm 1.0)$ & 0.564 & $(4.9 \pm 1.2)$ vs. $(5.3 \pm 1.6)$ & 0.059 \\
\hline Fearful & $(5.7 \pm 1.2)$ vs. $(5.7 \pm 1.1)$ & 0.317 & $(5.4 \pm 1.2)$ vs. $(5.6 \pm 1.3)$ & 0.102 & $(5.1 \pm 1.3)$ vs. $(5.3 \pm 1.4)$ & 0.102 \\
\hline Disgusted & $(5.2 \pm 1.2)$ vs. $(5.5 \pm 1.2)$ & 0.034 & $(4.2 \pm 1.4)$ vs. $(4.4 \pm 1.5)$ & 0.083 & $(4.4 \pm 1.5)$ vs. $(4.6 \pm 1.4)$ & 0.157 \\
\hline Angry & $(6.4 \pm 0.7)$ vs. $(6.5 \pm 0.7)$ & 0.157 & $(5.9 \pm 0.8)$ vs. $(6.1 \pm 0.9)$ & 0.102 & $(5.1 \pm 1.2)$ vs. $(5.5 \pm 1.1)$ & 0.109 \\
\hline Surprised & $(6.4 \pm 0.6)$ vs. $(5.6 \pm 0.9)$ & 0.157 & $(4.6 \pm 1.5)$ vs. $(4.8 \pm 1.5)$ & 0.157 & $(4.3 \pm 1.3)$ vs. $(4.5 \pm 1.3)$ & 0.157 \\
\hline Neutral & $(5.3 \pm 1.0)$ vs. $(5.6 \pm 0.9)$ & 0.066 & $(4.8 \pm 1.3)$ vs. $(4.7 \pm 1.2)$ & 0.317 & $(3.9 \pm 1.4)$ vs. $(4.0 \pm 1.4)$ & 0.492 \\
\hline
\end{tabular}

Wilcoxon Signed Rank Test was used for comparison of numerical data. Scores of recognized emotions are expressed as mean \pm standard deviation. Significant differences are demonstrated with bold characters. *declined ability to recognize related emotion. P: probability value, ExP: existential psychotherapy group, CBT: cognitive behavioral therapy group, SUP: supportive counselling group, vs: versus, Bgn: mean values before the start of sessions, Awk: mean values after weekly sessions, Abst: mean values after booster sessions

of time and effort on cognitive techniques in the second session as they did in later sessions. Their findings suggested that therapists substantially started to use congitive modification techniques as early as the second session of $\mathrm{CBT}^{48}$ Likely, we performed our work on the assumption that, cognitive improvement starts from early sessions and we finally decided a total of 10 sessions, 8 weekly, followed by two monthly. While cognitive improvement has a close interaction with improvement in FER, we hypothesized that, we may accomplish results after weekly sessions for FER. In view of the fact that, unlike CBT, there are not certain numbers of sessions offered for ExP and SUP, we decided to take the session number of CBT as reference, in order to provide the utmost uniformity. Thus, the session numbers for ExP and SUP were same with CBT.

Classical and third wave CBT were compared with various psychotherapy models for treatment of MDD. Some researchers argued that CBT was superior to other psychotherapies. ${ }^{49,50} \mathrm{CBT}$ alone was once known to be superior to $\mathrm{AD}$ alone for treatment of MDD. ${ }^{51}$ However, recent literature supports $\mathrm{CBT}$ combined with $\mathrm{AD}$ as first line treatment for $\mathrm{MDD} .{ }^{52} \mathrm{CBT}$ alone showed only marginally better improvement than $\mathrm{AD}$ alone, besides, severe depression was reported to be best treated with $\mathrm{CBT}$ and $\mathrm{AD}$ together. ${ }^{53} \mathrm{~A}$ metaanalysis reported that, $\mathrm{CBT}$ has lower rates of relapse and recurrence than $\mathrm{AD}$ after discontinuation of acute phase MDD treatment. ${ }^{54}$ Some researchers stated that, sequential use of CBT after pharmacotherapy may improve the long term outcome in recurrent depression. ${ }^{55}$ In a retrospective follow up of an earlier randomized controlled trial regarding residual symptoms of MDD, CBT was found to have short term but not long term benefits. ${ }^{56}$ In a different trial assessing the du- 
ration of CBT effect upon MDD, effects in prevention of relapse were found to persist, but with weakening, until 3 years after the end of CBT, and subsequent additional CBT was suggested to be explored. ${ }^{57}$ In the current trial, we demonstrated that, all three psychotherapy echoles led significant reductions in HDRS mean scores. However, while ExP and CBT had comparable effects on HDRS scores, they both provided more reduction than SUP group.

Taking into account all of these, while it remains unclear that CBT is superior to other psychotherapies for MDD, in addition to the comparement of final HDRS scores between groups, we hypothesized an indirect connection of preventive effect of CBT and certain other psychotherapies via FER.

As mentioned above, phenomenologic dialogue in ExP is not a directive process. It is a kind of work up for the process of openness to and looking out for experiences as a whole. ExP does not aim to reduce negative or enhance positive feelings and thoughts. Instead, ExP focuses on directing the patient to negotiate with all dimensions of experiences including feelings, thoughts, bodily senses and realities of the external world..$^{58}$ By this way, patient is encouraged to make choices, getting into the action and accepting and taking responsibility of all predictable and unpredictable outcomes. ${ }^{59}$ In the current trial, ExP enhanced the ability for recognizing facial emotions most, particularly for disgust, anger, surprise and neutral emotions. This finding may be due to the nontarget oriented structure of existential psychotherapy sessions, which makes room for wider range of emotions to be expressed and detailed in the sessions.

Some researchers reported comparable outcomes for SUP and CBT in the treatment of depression. ${ }^{60}$ In our trial, SUP had a relatively free content and the therapist was rather a friendly listener than a talker. When asked for an assistance concerning the choices about problems of daily life, SUP therapist answered with superficial and short comments in order to find possible choices of the patient together. At the end of the trial, difficulty to recognize facial emotions remained mostly unchanged in SUP group. Recognition of sad and angry emotions even got worse after weekly sessions with SUP (Table 8). This finding may partly be the conclusion of the friendly approach of SUP, which may have made room for patients to self justification and, so to say, passing the buck of life problems. Thus, they might have prioritized positive emotions and thoughts rather than negative ones and omit negative experiences to some extent.

In view of the information which indicates that depressed individuals have a tendency to perceive neutral stimuli as negative, ${ }^{61}$ unstructured psychotherapy approaches like SUP, even providing a nonspecific help for short term, did not seem to have a real effect on improving cognitions. Thus, we argue that, SUP might not be preventive enough against recurrences and relapses of MDD.

Understanding emotions from facial cues plays a fundamental role in the development of children's social competence. ${ }^{62}$ Children who understand facial emotional cues in social interactions have been found to form positive interpersonal relationships over time. ${ }^{63}$ Even neonates were observed to respond facial emotions. ${ }^{64}$ Certain configurations of facial features resulting from specific patterns of facial muscle movements are recognized as corresponding to particular basic emotions throughout the world. ${ }^{65,66}$

Individuals are capable of intentionally manipulating their emotional displays. They may follow display rules, which are proscriptions of their society as to what emotion should be displayed in given circumstances and how intensely it should be displayed. ${ }^{67}$ Children generally learn the predominant display rules of their culture over time. In a classic study concerning the development of display rules and control over emotional expressions, age-related changes were demonstrated in the ability of children to cover their dissapointment at the discovery that their gift for helping out an adult was much less interesting than the gift they had been expecting; the dissapointment of the younger children was too easier to detect. $^{68}$ Thus, the suggestion mentioned above in this paper which states the difference between spontaneous or overlearned emotional expressions to emotional stimuli in the presence of observers and controlled or posed emotional expressions as a function of display rules comes to scene again. Besides, cross-cultural studies of facial expressions performed by Ekman revealed that, certain cultural differences may have a role in facial expressions of different emotions. ${ }^{69}$ While the images in FERT belong to people from United States (US) and the responders in our study were Turkish and Sunni Muslims who might have display rules dissimilar to US citizens, the results may have been affected from these diversities.

Educating individuals about recognition of others' facial emotions may lead to a better mutual detection of emotions and then may provide more healthy cognitions and relationships. In turn, this education may have a preventive effect against relapse, recurrence or even the onset of MDD. Moreover, it presumably may facilitate remission.

In the current trial, patients who received ExP were found to have greater success on recognition of almost all facial emotions than beginning, while CBT group improved happy emotions only and SUP group did not improve any of them. Interenstingly, when each group were compared in themselves between weekly and booster sessions, only ExP group was found out to have a significantly greater success to recognize disgust and improvements close to statistically significance level for sad and neutral emotions. Thus, ExP seems to 
have a bigger improving effect on FER than other psychotherapies and this improvement seems to be ongoing. Therefore, we are arguing that, ExP might have a bigger effect on prevention of relapses and recurrences of MDD than $\mathrm{CBT}$ and SUP.

An unexpected outcome of this study was that, before sessions started, only surprised and neutral emotions were recognized better by healthy control group than patients. Other facial emotions, including happiness and sadness, did not differ. This finding should be detailed by trials with larger samples and may bring the classical data on cognitions of depressed patients into question.

The term "emotional intelligence (EI)" was originally conceptualised as the ability to perceive accurately, apraise and express emotion; the ability to access and/or generate feelings when they facilitate thought; the ability to understand emotion and emotional knowledge; and the ability to regulate emotions to promote emotional and intellectual growth. ${ }^{70}$ This definition seems to include the components of individual intelligence expressed by Gardner, mostly known of which are social intelligence and intrapersonal intelligence. ${ }^{71}$ While social intelligence can be conceptualised as the ability to perceive emotions, intentions and desires of others, intrapersonal intelligence can be described as the ability to reach own emotional environment. Here, the term alexithymia comes to the scene. We did not investigate alexithymia in the current trail, not to complexify our findings. However, alexithymic individuals were reported to have difficulty in recognizing facial emotions ${ }^{72,73}$ and to distinguish different emotional expressions. ${ }^{74}$ Thus, we suggest that, alexithymia might be a constitution to be searched alongside with FER in further studies.

Out of 95 patients included in the current study, 61 completed the whole protocol, and the rest 34 (35.8\%) did not. A metaanalysis regarding CBT drop-out rates, drop-out was operationally defined as attendence of more than one session but failure to complete all sessions. The overall findings were that, on average, every fourth person failed to complete therapy with drop-out ranging widely from $0 \%$ to $68 \% .{ }^{75} \mathrm{~A}$ more recent metaanalysis demonstrated that, drop-out from CBT occurs even before treatment starts, rising to an even higher level during treatment, total attrition rate accross both phases reaching about $35 \%{ }^{76}$ From this point of view, drop-out rate in the current study seems to be comparable with the rates reported until recently.

Our study has several limitations. First of all, photographs were not coloured. Coloured photographs could have had a positive effect on results of emotion recognition. Photographic films only were used for the process, but motion videos and analyses of facial muscle movements could have been a more descriptive application. CBT and ExP were performed by two therapists, while there was only one professional for SUP and this quantitative difference may be another limitation. Besides, while it had a relatively free content, we did not compose a brief manual or a flowchart for SUP, which may be seen as an additional limitation. Sample size and number of sessions were relatively small. Images belonged to US citizens while the responders were Turkish and Sunni Muslims.

In conclusion, the ability of depressive patients to recognize surprised and neutral facial emotions were lower than healthy controls. Patients who received ExP improved their ability to recognize almost all facial emotions, while difficulty to recognize emotions remained totally unchanged in SUP. CBT improved only happy emotions.

Ultimately, psychoeducation about recognizing facial emotions for individuals in risk group to undergo MDD and individuals who have MDD may be helpful for prevention, early diagnosis, treatment and follow-up. Moreover, psychoeducation of therapists about facial emotions may also provide beneficial effects.

ExP, CBT and SUP all led to a reduction in MDD. ExP and CBT had comparable effects and both were more helpful than SUP.

\section{Conflicts of Interest}

The authors have no potential conflicts of interest to disclose.

\section{Author Contributions}

Conceptualization: Onur Yılmaz, Ali Barlas Mırçık, Merve Kunduz, Müge Çombaş, Ahmet Öztürk, Erdem Deveci, İsmet Kırpınar. Data curation: Onur Yılmaz, Ali Barlas Mırçık, Merve Kunduz, Müge Çombaş. Formal Analysis: Onur Yılmaz, Ali Barlas Mırçık, Merve Kunduz, Müge Çombaş, Ahmet Öztürk, Erdem Deveci. Investigation: Onur Yılmaz, Ali Barlas Mırçık, Merve Kunduz, Müge Çombaş. Methodology: Onur Yllmaz, Ali Barlas Mırçık, Merve Kunduz, Müge Çombaş, Ahmet Öztürk, Erdem Deveci, İsmet Kırpınar. Project administration: Onur Yllmaz. Resources: Onur Yilmaz, Ahmet Öztürk, Erdem Deveci. Software: Onur Yılmaz, Ahmet Öztürk, Erdem Deveci. Validation: Onur Yllmaz, Ahmet Öztürk, Erdem Deveci, İsmet Kırpınar. Writing-Original draft: Onur Yilmaz, Ahmet Öztürk, Erdem Deveci. Writing_Review \& editing: Onur Yılmaz, Ahmet Öztürk, Erdem Deveci, İsmet Kırpınar.

\section{ORCID iD}

Onur Yllmaz https://orcid.org/0000-0002-8270-7354

\section{REFERENCES}

1. Ekman P. Lying and nonverbal behavior: theoretical issues and new findings. J Nonverbal Behav 1988;12:163-175.

2. Nowicki S, Duke MP. Individual differences in the nonverbal communication of affect: The diagnostic analysis of nonverbal accuracy scale. J Nonverbal Behav 1994;18:9-35.

3. Ekman P, Friesen WV. Nonverbal leakage and clues to deception. Psychiatry 1969;32:88-106.

4. Blair RJ. Facial expressions, their communicatory functions and neuro-cognitive substrates. Philos Trans R Soc Lond B Biol Sci 2003;358: 561-572. 
5. Prather MD, Lavenex P, Mauldin-Jourdain ML, Mason WA, Capitanio JP, Mendoza SP, et al. Increased social fear and decreased fear of objects in monkeys with neonatal amygdala lesions. Neuroscience 2001; 106: 653-658.

6. Anderson AK, Phelps EA. Expression without recognition: contributions of the human amygdala to emotional communication. Psychol Sci 2000;11:106-111.

7. Morris JS, Ohman A, Dolan R. A subcortical pathway to the right amygdala mediating 'unseen' fear. Proc Natl Acad Sci U S A 96 1999; 96:1680-1685.

8. Adolphs R. Neural systems for recognizing emotion. Curr Opin Neurobiol 2000;12:169-177.

9. Pizzagalli D, Regard M, Lehmann D. Rapid emotional face processing in the human right and left brain hemispheres: an ERP study. Neuroreport 1999;10:2691-2698.

10. Gur RC, Erwin RJ, Gur RE, Zwil AS, Heimberg C, Kraemer HC. Facial emotion discrimination: II. Behavioral findings in depression. Psychiatry Res 1992;42:241-251.

11. Persad SM, Polivy J. Differences between depressed and nondepressed individuals in the recognition of and response to facial emotional cues. J Abnorm Psychol 1993;102:358-368.

12. Machado PP, Beutler LE, Greenberg LS. Emotion recognition in psychotherapy: impact of therapist level of experience and emotional awareness. J Clin Psychol 1999;55:39-57.

13. Eack SM, Mazefsky CA, Minshew NJ. Misinterpretation of facial expressions of emotion in verbal adults with autism spectrum disorder. Autism 2015;19:308-315.

14. Dapelo MM, Surguladze S, Morris R, Tchanturia K. Emotion recognition in blended facial expressions in women with anorexia nervosa. Eur Eat Disord Rev 2016;24:34-42.

15. Daros AR, Ruocco AC, Reilly JL, Harris MS, Sweeney JA. Facial emotion recognition in first-episode schizophrenia and bipolar disorder with psychosis. Schizophr Res 2014;153:32-37.

16. Beck A, Rush A, Shaw B, Emery G. Cognitive Therapy of Depression. New York: The Guilford Press; 1979.

17. Beck AT. The current state of cognitive therapy: a 40-year retrospective. Arch Gen Psychiatry 2005;62:953-959.

18. Beck J. Cognitive Behavior Therapy: Basics and Beyond. New York: The Guilford Press; 2011.

19. Cuijpers P, Hollon SD, van Straten A, Bockting C, Berking M, Andersson $\mathrm{G}$. Does cognitive behaviour therapy have an enduring effect that is superior to keeping patients on continuation pharmacotherapy? A meta-analysis. BMJ Open 2013;3:e002542.

20. Podina IR, David D. Acceptance and Commitment Therapy. In: Vernon A, Doyle KA, Editors. Cognitive Behavior Therapies. Alexandria: American Counseling Association, 2017, p.177-208.

21. Greenberg J, Shapero BG, Mischoulon D, Lazar SW. Mindfulnessbased cognitive therapy for depressed individuals improves suppression of irrelevant mental-sets. Eur Arch Psychiatry Clin Neurosci 2017;267:277-282.

22. Steiner CJ, Reisinger Y. Understanding existential authenticity. Ann Tour Res 2006;33:299-318.

23. Schnell T. Existential indifference: another quality of meaning in life. J Humanist Psychol 2010;50:351-373.

24. Rae G. Sartre, Group Formations, and Practical Freedom. Realizing Freedom: Hegel, Sartre, and the Alienation of Human Being. London: Palgrave Macmillan UK, 2011, p.91-109.

25. Danner H. Existential responsibility-the civic virtue. Stud Philos Educ 1998;17:261-270.

26. Dearborn Nill J, Halling S. A brief history of existential-phenomenological psychiatry and psychotherapy. J Phenomenol Psychol 1995; 26:1-45.

27. Arnett RC. Toward a phenomenological dialogue. West J Speech Commun 1981;45:201-212.

28. Frankl VE. Logotherapy and existential analysis-- a review. Am J Psy- chother 1966;20:252-260.

29. Logos | philosophy and theology | Britannica.com. Available at: https:// www.britannica.com/topic/logos. Accessed June 20, 2018.

30. DiPetta G. Addictions and Depression: the Paradise Lost. Eur Psychiatry 2015;30(Suppl 1):114.

31. Ventegodt S, Clausen B, Langhorn M, Kromann M, Andersen NJ, Merrick J. Quality of life as medicine III. A qualitative analysis of the effect of a five-day intervention with existential holistic group therapy or a quality of life course as a modern rite of passage. ScientificWorldJournal 2004;4:124-133.

32. Reiter M, Chenail R. Behavioral, Humanistic-Existential and Psychodynamic Approaches to Couples Counseling. New York: Routledge; 2017.

33. Cuijpers P, Driessen E, Hollon SD, van Oppen P, Barth J, Andersson G. The efficacy of non-directive supportive therapy for adult depression: a meta-analysis. Clin Psychol Rev 2012;32:280-291.

34. Barth J, Munder T, Gerger H, Nüesch E, Trelle S, Znoj H, et al. Comparative efficacy of seven psychotherapeutic interventions for patients with depression: a network meta-analysis. Focus 2016;14:229-243.

35. First MB, Spitzer R, Giboobn M, Williams J. Structed Clinical Interview for DSM IV Axis Disorders (SCID-1) Clinical Version. Washington DC, London: American Psychiatric Press; 1997.

36. Özkürkçügil A, Aydemir Ö, Yılmaz M, Esen Danacı A, Köroğlu E. Adaptation to Turkish and Reliability Study of Structured Clinical Interview for DSM-IV Axis-1 Disorders. İlaç ve Tedavi Derg 1999;12:233236.

37. Hamilton M. A rating scale for depression. J Neurol Neurosurg Psychiatry 1960;23:56-62.

38. Williams JBW. A structured interview guide for the Hamilton Depression Rating Scale. Arch Gen Psychiatry 1988;45:742-747.

39. Akdemir A, Türkçapar M, Örsel S, Demirergi N, Dag I, Özbay M. Reliability and validity of the Turkish version of the Hamilton Depression Rating Scale. Compr Psychiatry 2001;42:161-165.

40. Zimmerman M, Martinez JH, Young D, Chelminski I, Dalrymple K. Severity classification on the Hamilton depression rating scale. J Affect Disord 2013;150:384-388.

41. Ekman P. Facial Expressions. In: Dalgleish T, Power M, Editors. Handbook of Cognition and Emotion. California: Wiley Publishers University of California, 1999, p.301-320.

42. Monroe S, Harkness K. Recurrence in major depression: a conceptual analysis. Psychol Rev 2011;118:655-674.

43. Scott J. Depression should be managed like a chronic disease. BMJ 2006;332:985-986.

44. Moffitt TE, Caspi A, Taylor A, Kokaua J, Milne BJ, Polanczyk G, et al. How common are common mental disorders? Evidence that lifetime prevalence rates are doubled by prospective versus retrospective ascertainment. Psychol Med 2010;40: 899-909.

45. Keller MB, Boland RJ. Implications of failing to achieve successful long-term maintenance treatment of recurrent unipolar major depression. Biol Psychiatry 1998;44:348-360.

46. Shapiro DA, Barkham M, Rees A, Hardy GE, Reynolds S, Startup M. Effects of treatment duration and severity of depression on the effectiveness of cognitive-behavioral and psychodynamic-interpersonal psychotherapy. J Consult Clin Psychol 1994;62:522-534.

47. Ilardi SS, Craighead WE. The role of nonspecific factors in cognitive-behavior therapy for depression. Clin Psychol (New York) 1994;1:138-155.

48. DeRubeis RJ, Feeley M. Determinants of change in cognitive therapy for depression. Cognit Ther Res 1990;14:469-482.

49. Eysenck HJ. The outcome problem in psychotherapy: what have we learned? Behav Res Ther 1994;32:477-495.

50. Shapiro DA, Shapiro D. Meta-analysis of comparative therapy outcome studies: a replication and refinement. Psychol Bull 1982;92:581-604.

51. Blackburn IM, Bishop S, Glen AI, Whalley LJ, Christie JE. The efficacy of cognitive therapy in depression: a treatment trial using cognitive therapy and pharmacotherapy, each alone and in combination. $\mathrm{Br} \mathrm{J}$ 
Psychiatry 1981;139:181-189.

52. Segal ZV, Grigoriadis S, Grigoriadis S, Ravindran AV, Kennedy SH, Lam RW, et al. Canadian Network for Mood and Anxiety Treatments (CANMAT) Clinical guidelines for the management of major depressive disorder in adults. II. Psychotherapy alone or in combination with antidepressant medication. J Affect Disord 2009;117(Suppl 1):S15-S25.

53. Thompson LW, Coon DW, Gallagher-Thompson D, Sommer BR, Koin D. Comparison of desipramine and cognitive/behavioral therapy in the treatment of elderly outpatients with mild-to-moderate depression. Am J Geriatr Psychiatry 2001;9:225-240.

54. Vittengl JR, Clark LA, Dunn TW, Jarrett RB. Reducing relapse and recurrence in unipolar depression: a comparative meta-analysis of cognitive-behavioral therapy's effects. J Consult Clin Psychol 2007;75:475-488.

55. Fava GA, Ruini C, Rafanelli C, Finos L, Conti S, Grandi S. Six-year outcome of cognitive behavior therapy for prevention of recurrent depression. Am J Psychiatry 2004;161:1872-1876.

56. Perlis RH. Cognitive behavioural therapy has short term but not long term benefits in people with residual symptoms of depression. Evid Based Ment Health 2005;8:75.

57. Paykel ES, Scott J, Cornwall PL, Abbott R, Crane C, Pope M, et al. Duration of relapse prevention after cognitive therapy in residual depression: follow-up of controlled trial. Psychol Med 2005;35:59-68.

58. Reker GT. Personal Meaning, Optimism, and Choice: Existential Predictors of Depression in Community and Institutional Elderly. Gerontologist 1997;37:709-716.

59. Kuhl J, Koole S. Workings of The Will, A Functional Approach. In: Greenberg J, Koole S, Pyszczynski T, Editors. Handbook of Experimental Existential Psychology. New York: The Guilford Press, 2004, p. 411-430.

60. Pybis J, Saxon D, Hill A, Barkham M. The comparative effectiveness and efficiency of cognitive behaviour therapy and generic counselling in the treatment of depression: evidence from the 2nd UK National Audit of psychological therapies. BMC Psychiatry 2017;17:215.

61. Gotlib IH, Krasnoperova E, Yue DN, Joormann J. Attentional biases for negative interpersonal stimuli in clinical depression. J Abnorm Psychol 2004;113:127-135.

62. Philippot P, Feldman RS. Age and social competence in preschoolers' decoding of facial expression. Br J Soc Psychol 1990;29:43-54.

63. Denham S. Emotional Development in Young Children. New York: The Guilford Press; 1998.

64. Meltzoff A, Moore M, Greenberg R, Cohen D. Interpreting imitative responses in early infancy. Science 1979;205:217-219.

65. Ekman P. Strong evidence for universals in facial expressions: a reply to Russell's mistaken critique. Psychol Bull 1994;115:268-287.

66. Dimberg U, Thunberg M, Elmehed K. Unconscious facial reactions to emotional facial expressions. Psychol Sci 2000;11:86-89.

67. Ekman P, Friesen WV. The repertoire of nonverbal behavior: categories, origins, usage, and coding. Semiotica 1969;1:49-98.

68. Saarni C. An observational study of children's attempts to monitor their expressive behavior. Child Dev 1984;55:1504-1513.

69. Ekman P. Cross-Cultural Studies of Facial Expression. In: Ekman P, Editor. Darwin and Facial Expression: A Century of Research in Review. Los Altos, CA: Malor Books, 2006, p.169-222.

70. Salovey P, Mayer JD. Emotional intelligence. Imagin Cogn Pers 1990; 9:185-211.

71. Gardner H. Multiple Intelligences: Prelude, Theory and Aftermath. In: Sternberg R, Fiske S, Foss D, Editors. Scientists Making a Difference. New York: Cambridge University Press, 2016, p.167-170.

72. Lane RD, Sechrest L, Reidel R, Weldon V, Kaszniak A, Schwartz GE. Impaired verbal and nonverbal emotion recognition in alexithymia. Psychosom Med 1996;58:203-210.

73. Parker JD, Taylor GJ, Bagby RM. Alexithymia and the recognition of facial expressions of emotion. Psychother Psychosom 1993;59:197-202.

74. Bagby RM, Parker J, Taylor GJ, Acklin M. Alexithymia and the ability to distinguish different emotional states. Psychother Psychosom 1993; 55:122.

75. Hans E, Hiller W. Effectiveness of and dropout from outpatient cognitive behavioral therapy for adult unipolar depression: a meta-analysis of nonrandomized effectiveness studies. J Consult Clin Psychol 2013; 81:75-88.

76. Fernandez E, Salem D, Swift JK, Ramtahal N. Meta-analysis of dropout from cognitive behavioral therapy: Magnitude, timing, and moderators. J Consult Clin Psychol 2015;83:1108-1122. 